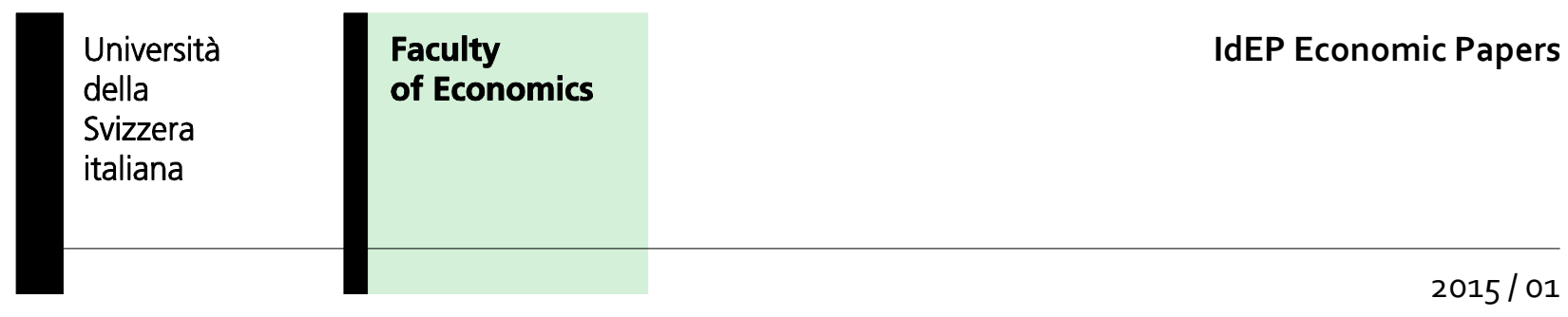

S. Galletta

Direct democracy, partial decentralization and voter information :

evidence from Swiss municipalities 


\title{
Direct Democracy, Partial Decentralization and Voter Information: Evidence from Swiss Municipalities*
}

\author{
Sergio Galletta ${ }^{\dagger}$
}

January 22, 2015

\begin{abstract}
In this paper I investigate whether changes in the availability of direct democratic institutions in local Swiss jurisdictions affect expenditure decentralization. By using a panel-based difference in differences estimation I find a statistically significant reduction in decentralization when the mandatory fiscal referendum is introduced at the local level. This result is consistent with the proposed theoretical framework. Direct democracy increases citizens' awareness of governments' behaviour which eventually affects politicians' electoral incentives. When officials from two different levels of government share the responsibility for the provision of public goods, they find it convenient for electoral purposes to favor expenditures where citizens have the lowest control over government actions.
\end{abstract}

$<$ Tables and figures at the end $>$

JEL Classification H76, H77, D72, D78

Keywords Direct Democracy, Fiscal Referendum, Partial Decentralization, Vertical Interaction

\section{Introduction}

Recently there has been a growing interest in direct democratic institutions as an instrument for sub-federal jurisdictions to remodel their relationships with central authorities.

${ }^{*}$ I wish to thank David Agrawal, Katherine Cuff, Patricia Funk, Vincenzo Galasso, Mario Jametti, Marcelin Joanis, Michael Devereux, Raphaël Parchet and Francesco Trebbi for their insightful comments and Marco Tarchini for his excellent assistantship. I have also benefited from comments by participants at the Sinergia Workshop (Lausanne), the IIPF (Lugano) and the CPEG (Ottawa). Financial support from the Swiss National Science Foundation (grants ProDoc - 130443 and Sinergia - 130648 / 147668 ) is gratefully acknowledged.

${ }^{\dagger}$ Institute of Economics (IdEP), University of Lugano, Via G. Buffi 6, 6904 Lugano, Switzerland; e-mail: sergio.galletta@usi.ch. 
For example, in the European Union many sub-national jurisdictions use referenda on independence as a shortcut, or threat, to reach a higher autonomy from the central government (e.g., Scotland in UK, Cataluña in Spain and Veneto in Italy). Of the same nature is the referendum promised by the UK prime minister David Cameron about the intention to leave the European Union.

Interestingly, only a few papers have assessed the effect of direct democracy on fiscal decentralization. In a theoretical contribution Redoano and Scharf (2004) suggest that centralization of tasks is more likely to occur under a representative democracy. However, the only two empirical analyses have produced conflicting results. On the one hand, Feld et al. (2008) show that Swiss cantons (states) which allow for fiscal referenda experience a higher level of decentralization. On the other hand, Funk and Gathmann (2011), again using a sample of Swiss cantons, conclude that direct democratic institutions produce no effects on the allocation of public expenditure between levels of government.

Although the two empirical applications are different in terms of period of time considered and identification strategy used, they both focus on a measure of decentralization aggregated at the state level. The latter point constrains the analysis since variations of direct democratic institutions at the local level cannot be taken into account. Such a condition would not be an issue if local authorities in Switzerland acted as pure agents following decisions taken by higher level jurisdictions (i.e., cantonal and federal governments). This, however, is not the case: Swiss municipalities play a central role in determining expenditure decentralization as opposed to hierarchical subservience.

Therefore, this analysis wants to identify the effect of direct democracy on decentralization and, to add to the current body of works on the subject, this paper focus on local level institutions. In order to do so, I employ a difference in differences analysis on a panel of 406 Swiss municipalities for a period of 20 years. Among these municipalities, 45 either introduced or abolished one of the more relevant direct democratic institutions in Switzerland, namely the mandatory referendum on new expenditure. I show that direct democracy at the local level decreases expenditure decentralization and the amount of transfers that a lower level jurisdiction receives from the state level. These results are robust to a variety of controls and, most importantly, they are still valid after I control for possible task assignment and direct democratic institutional changes at the cantonal level. In addition, I apply different strategies that allow me to suggest a causal relationship between direct democracy and decentralization.

These conclusions are in line with the prediction of a companion theoretical analysis. In Switzerland, as in other countries, expenditure decentralization is mainly determined by the tasks that are assigned at each level of government. However, Swiss citizens are called to vote in favor or against a decision that aim at changing any pre-existent condition, which means that task assignment does not boil down to a representative versus direct democracy issue. For this reason, I set up a simple theoretical model linking direct democracy and 
decentralization by moving the intuition from the effect that direct democracy might have on task assignment to the effect that direct democracy should have on governments' electoral incentives and consequently on discretionary expenditures.

As such, I follow the political economy model from Joanis (2014) by putting substantial attention on the vertical interaction between governments. In Switzerland, public goods are often provided in a condition of partial decentralization where at least two levels of government are jointly responsible for policy outcomes. Hence, governments have common electoral incentives and citizens have imperfect information on each government's behavior. Nevertheless, the latter point can be affected by the presence of direct democratic institutions which are expected to foster an increased availability of information (Benz and Stutzer, 2007; Matsusaka, 2005). In this environment, both levels of government will find it convenient to move expenditure to where politicians are less exposed to citizens' scrutiny, eventually affecting the actual level of decentralization.

As a result, direct democratic institutions should produce two opposite effects depending on whether its influence on the information available to citizens is stronger at the local or state level. Direct democracy positively affects decentralization if it is stronger at the upper level, whereas it negatively affects decentralization if it is stronger at the lower level. My analysis confirms the latter prediction while, as already pointed out, the former one is confirmed by Feld et al. (2008) and rejected by Funk and Gathmann (2011).

The remainder of the paper is organized as follows. Section 2 introduces to the relevant literature. Section 3 provides institutional background on Switzerland. Section 4 outlines the model and the testable hypothesis, while Section 5 describes the dataset and the empirical strategy. The results along with further robustness checks are reported in Sections 6 and 7 . Section 8 concludes.

\section{Related literature}

This paper is mostly related with two distinct strands of literature. First, it is associated with those studies that follow a political economy perspective in the analysis of decentralization. This literature is also known as second generation theory of fiscal federalism (Oates, 2005). The main results show how political incentives can be important from either a normative or a positive analysis of decentralization. ${ }^{1}$ Second, there is a clear relation with research that aims at finding how different decision-making processes affect public policies. This research shows how countries allowing for direct legislation produce economic outcomes that differ from the ones of pure representative democracies. ${ }^{2}$

Although the two above mentioned strands of literature have independently produced

\footnotetext{
${ }^{1}$ See for example, Besley and Case (1995), Besley and Coate (2003), Bordignon et al. (2003), Brülhart and Jametti (2006) and Kotsogiannis and Schwager (2008).

${ }^{2}$ See for example, Matsusaka (1995), Gerber (1996), Feld and Matsusaka (2003), Matsusaka (2005) and Hinnerich and Pettersson-Lidbom (2014).
} 
copious results, only a few studies predict how decision making process institutions (i.e., direct vs. representative democracy) can define the extent of fiscal decentralization.

From a theoretical point of view Redoano and Scharf (2004) look at the process of centralization of tasks. In a two-jurisdiction model of public good provision, they compare the outcome of this process under decisions taken directly by citizens and decisions taken by elected representatives, respectively. The authors consider centralization as a form of policy equalization across regions which occurs only if both jurisdictions are in agreement. They show that centralization has a higher probability of success when the decisions are taken through representative rather than direct democracy. Specifically, voters from a procentralization jurisdiction can affect delegates' conduct from a reluctant jurisdiction by choosing representatives which present similar preferences. The same is not possible if the decision is taken by a direct referendum.

This prediction focuses on situations in which task assignment boils down to a representative versus direct democracy issue. This is not the case with regard to Switzerland where, as in many other countries, task assignment is fairly stable over time and defined in federal and sub-federal constitutions. However, Swiss citizens are called to vote in favor or against any change decided to existent constitutions, which means that task assignment is essentially decided solely through direct legislation. Therefore, in order to better assess Swiss institutions, unlike Redoano and Scharf (2004), I propose a model where task assignment is assumed to be given and has a minor role in determining the different levels of decentralization that one might verify under different decision making processes.

For this reason, following Joanis (2014), I assume decentralization to be endogenously determined and largely affected by political electoral incentives. He produces a theoretical analysis assuming a condition of partial decentralization where more than one level of government provide a specific public good. The model is structured as a pure moral hazard political agency model. Strategic behaviour arises because of asymmetric information of governments with respect to voters, which eventually triggers a reduction on the accountability benefits of decentralization. The primary results predict that decentralization is dependent on relative rents from holding office, besides political conditions and competence of both levels of government. ${ }^{3}$

However, unlike Joanis (2014), the proposed theoretical framework throughout this paper exploits the role of direct democracy as a determinant of decentralization. In addition, given that the model has mainly an heuristic purpose, I focus only on one of the plausible theoretical channels, suggested by Matsusaka (2005), through which direct democracy affects public policies. According to the author there are three mechanisms through which direct democracy affects public policies: a reduction in the political agency problem, a higher quality of information and a reduced possibility of logrolling. ${ }^{4}$ I only take into account direct

\footnotetext{
${ }^{3}$ Jametti and Joanis $(2011,2014)$ empirically confirm the model's predictions.

${ }^{4}$ With respect to these three channels, Redoano and Scharf (2004) can be considered a good example of
} 
democracy as an instrument capable to positively affect citizens' information on politicians.

Two empirical analyses have been done to test the effect of direct democracy on decentralization. Both Funk and Gathmann (2011) and Feld et al. (2008) show results by using data on Swiss cantons. The latter confirm the hypothesis that direct democracy encourages decentralization, while the former did not find any significant effect of direct democracy on the level of decentralization. One of the main differences in these two studies is the identification strategy. Feld et al. (2008) consider direct democracy as a predetermined characteristic of cantons suggesting that endogeneity is a minor issue. Given this assumption, they rely on a pooled cross section - time series analysis where a high number of controls are used to compensate for the absence of fixed effects. Funk and Gathmann (2011), instead, allow the effect to be identified by those jurisdictions that experienced an institutional change over the 100-year period they consider. To do so, they control for unobserved heterogeneity among jurisdictions by using fixed effects at the cantonal level. Further they tackle the potential endogeneity issue by providing an instrumental variable approach in which they instrument direct democratic institutions on the availability of the same institution in neighbouring cantons and with the number of signatures needed to launch a constitutional initiative.

This paper attempts to complement the main limit of both studies, which rely on the lack of analysis on all Swiss sub-federal jurisdictions. Indeed, as I will explain in more detail in Section 3, both Swiss cantons and municipalities experience large autonomy in controlling the availability of direct democratic institutions as well as in tax setting and public expenditure decisions. Therefore, the institutional settings of local jurisdictions are likely to be important in defining decentralization.

This study also complements Galletta and Jametti (2012). Here, the authors look at the effect of direct democracy on municipal expenditure by allowing for variations of institutions over the two levels of government involved in the provision of public goods. They find that direct democracy at the state level is correlated with higher local public expenditure. However, this positive effect is lower when the local government is availed of direct legislation. Thus, the vertical interaction of different decision-making process seems to play a role as well.

\section{The Swiss institutional setting}

Switzerland is a federal country with three levels of government: national, cantonal and municipal. Each tier has a similar share of total expenditure and revenue. This situation has been quite stable over time: considering the period 1990-2009 the expenditure (revenue) shares averaged $32 \%$ (31\%) for federal, $41 \%$ (41\%) for cantonal and $27 \%$ (28\%) for local administrations. Moreover, sub-central jurisdictions experience large autonomy in setting how direct democratic institutions affect decentralization by reducing the possibility of logrolling which are present in a pure representative democracy 
both expenditures and revenues. In general, both cantons and municipalities levy taxes on personal income and wealth as well as corporate income and capital. Note that the largest contributions of revenue come from taxes on personal income.

Although a recent reform proposed a clearer division of tasks between cantonal and federal levels, still, many tasks are jointly carried out with contributions from all levels of government. ${ }^{5}$ Nevertheless, if not explicitly defined in the Swiss constitution, decisions concerning the actual division of tasks are mainly taken by cantons. Table 1 shows the financial effort, of cantons and municipalities, for different categories of public services.

All three levels of government democratically elect executive and legislative branches. ${ }^{6}$ Moreover, they can provide a variety of direct democratic instruments at the citizens' disposal. Once again, the available instruments vary depending on the canton and municipality considered, as defined by the constitution of each jurisdiction. ${ }^{7}$

Apart from the communal assembly, initiatives and referenda are the most common instruments of direct democracy. Through initiatives, citizens directly promote new laws, or the modification of old ones, while referenda allow them to confirm or deny a previous decision taken by the legislative branch. A referendum can be optional or mandatory. In the first case, the referendum takes place only after citizens collect a certain number of signatures within a defined interval of time, while in the latter all new decisions have to be confirmed by popular vote.

As part of the empirical analysis, I consider mandatory fiscal referendum on new expenditure, similar to precedential research. Notably, for sub-central jurisdictions this is a predominant type of referendum. This type of budget referendum makes it compulsory for governments to ask citizens the approval for any specific expenditure (once or repeated) that exceeds a given threshold.

Before moving to the following sections, it is worth noting an important aspect that affects, for different reasons, both the theoretical model and the empirical application of this paper: in each level of government, a constitutional reform requires in principle the citizens' approval. In other words, both task assignment and direct democratic institutions availability depend on citizens decisions. From a theoretical perspective, this forces me to move away from the intuition of Redoano and Scharf (2004) and to assume task assignment as a predetermined condition with respect to the mechanisms defining the actual level of expenditure decentralization. As for the empirical aspect, I must deal carefully with the

\footnotetext{
${ }^{5}$ In 2004 citizens approved the so called "Neugestaltung des Finanzausgleichs und der Aufgabenteilung" which entered in force 2006 .

${ }^{6}$ In many small municipalities the legislative branch is the communal assembly in which decisions are taken directly by citizens. There are also municipalities in which both the municipal council and the assembly coexist.

${ }^{7}$ According to cantonal laws, municipalities might present limited autonomy in deciding reforms to the already available direct democratic institutions. Indeed, Micotti and Bützer (2003) note that municipalities belonging to non-German speaking regions are largely constrained to use those instruments dictated by the cantons.
} 
potential endogenous decision of a municipality to reform direct democratic institutions.

\section{Model}

\subsection{The economic framework}

To be consistent with the Swiss institutional setting, the theoretical structure draws on Joanis (2014) where the vertical interaction of different governments' characteristics have been found to present a major impact on decentralization.

There are two time periods $t=1,2$ and two levels of government $i=s, l$ (state and local) that jointly provide a public good $g$ in a given local jurisdiction where citizens have homogeneous preferences. ${ }^{8}$ Citizens' preferences are characterized by a quasi-linear utility function.

$$
u(g, c)=g^{\sigma}+c
$$

where $0<\sigma<1$ while $g$ and $c$ are the consumption of a public and a private good respectively.

The output of the public good is given by a CES production function in which the inputs depend on the contribution of each level of government:

$$
g=\left(\left(g^{s}\right)^{\theta}+\left(g^{l}\right)^{\theta}\right)^{\frac{1}{\theta}}
$$

where $0<\theta<1$, which implies that the inputs are not perfect substitutes. It is worth noting that, differently from Joanis (2014), the two governments are assumed to be equally competent in the provision of the public good.

Each government levies a lump sum tax $x^{i}$ such that

$$
X=x^{s}+x^{l}, \text { with } x^{i}=\tau g^{i},
$$

is the amount that citizens devote to taxes. $\tau$ is the unit cost of production, which is assumed to be equal for both levels of government.

Finally, all citizens have an endowment of the private good, $y$, which is either consumed or used to pay taxes

$$
y=X+c .
$$

\subsection{Politicians, voters and elections}

Governments from the two levels are assumed to obtain utility from being in office. In other terms, politicians seek reelection because they receive "ego-rents" from holding office (e.g., the prestige of power).

\footnotetext{
${ }^{8}$ Given that citizens are homogeneous the population is normalized to one.
} 
Let us assume that the cost of production, $\tau$, is unknown by voters. Further, voters have imperfect information on each government's contribution to the provision of public good $g^{i}$ and, in addition to Joanis (2014), on the actual level of public good, $g$.

With reference to these assumptions, a crucial point in the model is played by the interrelation between the decision making process and voters' information about the actions of politicians. The ability of voters in to understand the real spending effort exerted by each government is strongly related with the type of decision making process they experience. Here, it is assumed that direct and representative democracy imply different outcomes in terms of citizens' information about political issues. While in the former, decisions are taken directly by citizens, or at least they are responsible to confirm politicians' decisions, in the latter, officials act with no immediate control. Information is more easily accessible under direct democracy because it allows both a higher level of transparency and a higher participation in the public debates preceding policy decisions. Benz and Stutzer (2007) provide detailed empirical and theoretical findings that validate this argument.

I develop this basic insight by introducing in the model $\delta^{i} \in[0,1]$, which is a parameter positively related with the availability of direct democratic institutions in a jurisdiction. The closer $\delta^{i}$ is to 1 , the greater the citizen's capacity to clearly assess the level of public expenditure. Both governments know the values of these parameters while citizens, though aware of the relationship between $\delta$ and information transparency, cannot observe their actual values. Hence, by taking into account the effect of direct democracy on information, citizens are expected to observe $\tilde{g}^{i}=\left(\delta^{i}\right)^{-1} g^{i}$ from a contribution $g^{i}$. It is worth noting that, for all values of $\delta, \tilde{g}^{i}>g^{i}$. Therefore, there is the implicit assumption that voters will systematically overestimate public expenditure. This is coherent with a situation in which voters trust incumbents' pre-electoral announcement about implemented policies while politicians, by behaving rationally, claim a level of expenditure higher than the actual one.

Finally, I assume that elections take place at both levels at the end of period 1 . Therefore, voters will elect, at each level, either the incumbent or the challenger to be in power in period 2. I assume that the probability of reelection is positively related to the perceived utility $\tilde{u}(\tilde{g}, c)$ according to a function $F(\tilde{u})$, where $F^{\prime}>0, F^{\prime \prime}<0$ and $0<F(\tilde{u})<1$. As in Joanis (2014) one might interpret the function $F$ as the probability that the utility experienced by citizens is higher than a random threshold that would make citizens willing to reelect the incumbent. Therefore, even if the probability of reelection depends on $F$ for both levels, one might still expect divergent election outcomes between the two governments because of the randomness of the election rule. Hence, each government will choose $g^{i}$ such that it maximizes its own probability of reelection. All considered, reelections will be affected by the decision making process at both levels of government eventually determining the level of decentralization. 


\subsection{Decentralization equilibrium}

The model can now be solved to derive the equilibrium level of decentralization in the first period of the game.

Remembering that governments have to take into account citizens' assessment on each level of contribution, instead of the real effort, we obtain:

$$
\max _{g^{i}} F\left(\left(\left(g^{i}\left(\delta^{i}\right)^{-1}\right)^{\theta}+\left(g^{-i}\left(\delta^{-i}\right)^{-1}\right)^{\theta}\right)^{\frac{\sigma}{\theta}}+y-\tau\left(g^{i}+g^{-i}\right)\right),
$$

From the first order conditions of the maximization problem in (5) we get the two best response functions

$$
\begin{aligned}
& 0=F^{\prime}(\cdot)\left[\sigma\left(\delta^{l}\right)^{-1}\left(g^{l}\left(\delta^{l}\right)^{-1}\right)^{\theta-1}\left(\left(g^{l}\left(\delta^{l}\right)^{-1}\right)^{\theta}+\left(g^{s}\left(\delta^{s}\right)^{-1}\right)^{\theta}\right)^{\frac{\sigma}{\theta}-1}-\tau\right], \\
& 0=F^{\prime}(\cdot)\left[\sigma\left(\delta^{s}\right)^{-1}\left(g^{s}\left(\delta^{s}\right)^{-1}\right)^{\theta-1}\left(\left(g^{l}\left(\delta^{l}\right)^{-1}\right)^{\theta}+\left(g^{s}\left(\delta^{s}\right)^{-1}\right)^{\theta}\right)^{\frac{\sigma}{\theta}-1}-\tau\right],
\end{aligned}
$$

for the local and the state government, respectively.

By solving equation (6) and (7) for an interior solution, we find the spending ratio of equilibrium in a specific local jurisdiction:

$$
\frac{g^{l}}{g^{s}}=\left(\frac{\delta^{l}}{\delta^{s}}\right)^{\frac{\theta}{\theta-1}} \approx D E C
$$

is the main component in the usual definition of decentralization (i.e., $\frac{g^{l}}{g^{l}+g^{s}}$ ).

By looking at Equation (8), both $\delta^{l}$ and $\delta^{s}$ play a central role in determining how much a municipality spends in its territory compared to how much the state spends there. Noting that the exponent is negative, the higher (lower) the value of $\delta^{l}$, due to the presence (absence) of direct democratic institutions at the local level, the lower (higher) the level of decentralization. On the contrary, the higher (lower) the value of $\delta^{s}$, the higher (lower) the level of decentralization. The strength of these relationships depends on $\theta$, which captures the degree of complementarity between the public goods provided by the two tiers of governments. Therefore, the higher the value of $\theta$ (i.e., a lower complementarity level), the stronger the effect of changes in the value of $\delta^{l}$ and $\delta^{s}$ on decentralization.

How do we explain this result? Citizens vote for the incumbent when they perceive that spending in the public goods is adequate to satisfy their preferences. However, citizens' beliefs about the provision of public goods are affected to a large extent by the availability of transparent information. In the model, this hinges on the presence of direct democratic instruments. Thus, each government finds it convenient to allocate expenditure to the level 
that has the lowest presence of direct democratic instruments so that it can claim a higher level of expenditure (i.e., a higher supply of public services) during the electoral campaign. By doing so, they both increase their probability of reelection. Indeed, for a given level of expenditure $g^{i}$, the lower $\delta^{i}$ (i.e., absence of direct democratic institutions), the higher the positive effect on the probability of election. However, this mechanism depends also on the level of complementarity between the services provided by the two governments: the higher the level of substitutability, the stronger the effect of direct democracy on decentralization as it is less expensive to move expenditure from one level to another.

Hypothesis - The introduction (or strengthening) of direct democratic institutions at the local level decreases decentralization, while the introduction (or strengthening) of direct democratic institutions at the state level increases decentralization.

In the following sections I empirically test the first part of the hypothesis by using changes to Swiss direct democratic institutions that occurred at the local level (municipalities).

\section{$5 \quad$ Data and empirical model}

\subsection{Data}

The selection of my sample is the result of a number of steps that allow me to produce one of the largest available datasets about Swiss municipalities including information that refers to both institutional and public budget components.

This task has been accomplished under the Sinergia project "The Swiss Confederation: A Natural Laboratory for Research on Fiscal and Political Decentralization" (n. 130648 / 147668) funded by the Swiss National Science Foundation. Initially, we have been provided fiscal information of nearly 700 municipalities for the period 1990-2009 by the Swiss Federal Department of Finance. ${ }^{9}$ To rely on a consistent set of data, I select those municipalities meeting the following criteria: first, they have provided information on categorical expenditure for at least 15 years in the 20-year period considered; second, they have not experienced either a merge with other municipalities, or a split, again in the 20-year period.

Unfortunately, in Switzerland, institutional details at the municipal level are not easy to collect given that it does not exist any accessible unified database. Therefore, information is included initially regarding the presence of the mandatory referendum on new expenditure from Bützer (2007), which provides a detailed description of direct democratic institutions

\footnotetext{
${ }^{9}$ These are official, but not published. More in detail, the data on public expenditure I am using are taken from a survey done by the Swiss Ministry of Finance in 2009 in which it has been asked to a large sample of municipalities to fill a form with detailed information on their balance from 1990 to 2009 by following an updated version of the "Chart of Accounts and Functional Classification".
} 
for 54 municipalities that belong to the sample. Secondly, 425 municipalities were contacted by e-mail asking to provide all the different versions of the municipal constitutions in force starting from 1990. Eventually, answers from 352 municipalities were received, which provided information for at least two years. We reported a rate of response of $83 \%$. From these laws we completed a careful codification of the availability of mandatory referendum on new expenditure as well as an examination of the cantonal constitution when a municipality specifically refers to it.

To sum up, I avail of an unbalanced panel of 406 Swiss municipalities belonging to the 26 Swiss cantons considering yearly observations for the 20-year period from 1990 to 2009 inclusive. $^{10}$

In the empirical analysis, the main dependent variable considers the share of municipal per capita public expenditure of the total municipal and cantonal per capita public

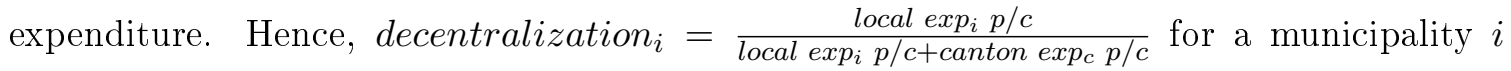
in a canton $c$. Ideally, for coherence with the theoretical framework, I should have used a dependent variable taking into account both municipal and cantonal expenditure for a given municipality, such that decentralization ${ }_{i}=\frac{\text { local exp }_{i}}{\text { local exp }_{i}+\text { canton exp }_{i}}$. Unfortunately, this kind of information is not available in Switzerland due to state level expenditures being not directly imputable to a specific municipality. Therefore, my dependent variable relies on the assumption that citizens from one canton, regardless the municipality of residence, experience the same cantonal amount of public good provision.

Funk and Gathmann (2011) and Feld et al. (2008) have a similar limitation when considering aggregate centralization measure as a dependent variable. Basically, they assume that each municipality in a canton has the same level of per capita expenditure.

Therefore, while this analysis adds to the body of work on the subject important information on the availability of direct democratic institutions at a municipal level, it is still constrained by missing information on cantonal expenditure. To circumvent this restriction, I use an alternative dependent variable that takes into account specific cantonal financial support for each municipality. Share of transfers is the ratio between the municipal revenue from cantonal transfers and municipal expenditure. This variable acts to complement some of the limits of decentralization by making it possible to link the availability of direct democracy in a specific municipality and a fiscal decision taken at the cantonal level that concerns exactly that municipality.

The main explanatory variable is mandatory ref., which is equal to 1 if a municipality avails itself of the mandatory referendum on new expenditure and 0 otherwise. Given to the larger number of municipalities considered in my dataset, and contrary to previous research, I found several institutional changes at the municipal level. Indeed, changes occurred only in small municipalities, while the largest ones seem to have a more stable institutional setting. Table 2 reports the numbers of municipalities by canton and the changes in institutions that

\footnotetext{
${ }^{10}$ Switzerland had 2596 municipalities at the beginning of 2010.
} 
were verified during the 20-year period considered at both municipal and cantonal level.

In the sample, 45 of the 406 municipalities changed their institutions (40 introduced and 5 abolished the referendum). Figure 1 shows a map of the municipalities and where they are located in Switzerland. Although not directly addressed, cantonal institutions are also taken into account. Overall, changes in cantonal institutions occurred in 7 out of 26 cantons (Zurich, Bern, Obwalden, Neuchatel and Valais abolished the referendum; Aargau introduced it; Vaud first introduced and then remove it).

I include also socio-economic and political controls at the municipal level. By controlling for Population I allow for economies of scale in the provision of public goods and control for potential mechanical effects due to the dependent variable that reports a per capita measure. Dependency ratio and share of foreigner is included to shape citizens' preferences concerning the provision of public goods. I also included the percentage of votes received by the left-wing parties and the turnout in the closest national election. While the first variable is a proxy for political preferences of citizens, the second is a control for the degree of their involvement in the political activity.

Finally, as reported in Table 3, I consider municipal fixed characteristics from the first year of my panel to study the reasons why a municipality chooses to introduce a referendum. These variables are either per se fixed (i.e., area, urban, urban center, touristic center and lake) or they represent municipal population's condition as revealed by the Swiss census from the year 1990 (i.e., share pop. German speakers, share pop. primary sector, share pop. inactive, share pop. university degree and share pop. protestant).

\section{$5.2 \quad$ Empirical model}

My aim is to identify the average impact of a municipal fiscal mandatory referendum on decentralization. To do so I apply a linear regression model with a difference in differences estimator where the treatment is the introduction of a fiscal mandatory referendum at the local level. Therefore, the sample is composed by a treated group of 45 municipalities that have decided to introduce or abolish the referendum, and a control group of 361 municipalities that do not change their institutional setting. In other words, I compare the variation in decentralization in the treatment group before and after the reform to the variation in decentralization in the control group. This strategy allows to control for both observable and unobservable time-invariant heterogeneity at a municipal level, which could be correlated with the decision to reform and with the degree of decentralization.

Formally, the model I estimate is:

$$
Y_{i c t}=\alpha_{i}+\lambda_{t}+\chi_{c t}+\gamma_{i} t+\beta M u n R e f_{i t}+\delta \mathbf{X}_{i c t}+\epsilon_{i c t}
$$

where $i$ denotes the municipality, $c$ the canton and $t$ the year. The dependent variable $Y$ is the level of decentralization of expenditure. MunRefit is a dummy variable with value 1 or 
0 whether the municipality respectively avails or not of a mandatory fiscal referendum. $\alpha_{i}$ are municipal fixed effects and $\lambda_{t}$ are year effects. $\chi_{c t}$ are canton-by-year fixed effects and $\gamma_{i} t$ are municipal specific time trends. $X_{i c t}$ are other control variables and $\epsilon_{i c t}$ is the error term.

Find a causal effects in this analysis is a challenging objective. The main concern, is that municipal characteristics that vary over time are correlated with both decentralization and the decision to reform. Although in section 5.2.1 I deal more formally with this issue, the main analysis produces already rather robust results because it controls for a large portion of municipal time-varying characteristics.

First, given that I rely on a panel data-set, I use municipal linear time trends. By doing so I take care of the key parallel trend assumption and I control for both idiosyncratic temporary shocks and differentials in macro trends.

Further, I include controls that allow me to better assess citizens' preferences. Interestingly, Funk and Gathmann (2013) find that direct democracy is stronger in those cantons that are less supportive of public spending. One might expect that a similar relationship holds for local jurisdictions too. Therefore, I control for voters' preferences by using the share of votes in favor of left-wing political parties during national elections. Municipalities with a strong preference for these parties might be more likely to prefer redistribution and a higher level of expenditure (i.e., less fiscally conservative). In absence of such a control, I might overestimate the effect of a municipal referendum on decentralization.

Finally, I introduce canton-by-year fixed effects. These terms allow me to absorb any source of omitted variables at a cantonal level. The most important consequence is that they also control for changes in task assignments as well as changes in the availability of direct democratic institutions which occurred in all cantons for the time period considered. As predicted by the theoretical model, decentralization should depend on the strength of direct democratic institutions at both levels, under the assumption that task assignment is predetermined (or exogenous). Therefore, the reliability of the analysis might be largely reduced by omitting these controls.

In all the estimations, I use standard errors clustered two-ways by municipality and year to adjust for any possible correlation in the error term due to the panel structure (Cameron et al., 2011).

\subsubsection{Causality}

The empirical strategy described so far controls for both time-invariant unobservable and some important time-varying observable heterogeneity. However, the decision of a municipality to introduce a fiscal referendum might be still correlated with time-varying unobservable features that also affect decentralization. Therefore, to produce causal estimates it needs to be shown that the timing and the decision to introduce a fiscal referendum appears to be random conditional on the controls. A well-designed instrumental variable approach 
would be a natural strategy to deal with such an endogeneity issue. For example, Funk and Gathmann (2011) use an instrumental strategy that relies on potential spatial correlation between municipal institutions. They instrument direct democratic institutions by considering the presence of the same institution in neighbouring jurisdictions. Ideally, I would use the same approach, but my sample does not allow me to have information on all neighbouring jurisdictions of a specific municipality. Therefore, I might produce results that are biased given that the instrument would be based on incomplete information. Nevertheless, I apply a number of strategies in order to reduce the concern of endogeneity.

First, I estimate a discrete-time duration model of the probability of introducing a fiscal referendum, following the procedure described by Jenkins (1995). Hence, I try to exploit the reasons that make municipalities choose to reform. I consider the probability of applying this reform as a function of both fixed pre-treatment characteristics and timevarying municipal characteristics. The latter group includes time-differences of the main covariates and decentralization such that I test whether changes in these observable timevarying variables affect the probability of reforming direct democratic institutions. The aim of this analysis is to verify whether reforms are mainly dependent on fixed pre-treatment attributes or on other important observed variables that change over-time. Therefore, if I find that changes in institutions are not due to the second set of characteristics, I should be less worried about the omitted variable bias given that the presence of correlation between the decision to introduce a fiscal referendum and other municipal time-varying unobserved characteristics is less likely. ${ }^{11}$

Second, I look at the relative size of the omitted variable bias as suggested by Oster (2014), which follows the work by Altonji et al. (2005). By assuming the selection on observables as proportional to the selection on unobservables, I show how large it has to be the effect of unobservable characteristics so that the expected effect of the referendum on decentralization is canceled out. The greater the measure of influence has to be, the lower is the concern about the presence of important omitted variable bias. In addition, an identification set for the treatment effect is computed to check whether it excludes coefficient equal to zero for mandatory ref.. Specifically, I produce these tests by considering the procedure described by Oster (2014). As an improvement with respect to Altonji et al. (2005), this methodology takes into account, along with the variation of the estimated coefficient of interest due to the inclusion of additional controls, also the shift of R-squared. In other words, I compare the change of mandatory ref. coefficient and R-squared from one uncontrolled regression and a number of controlled regressions.

Finally, I follow an approach in the spirit of a Granger (1969) test of causality as suggested by Angrist and Pischke (2009). This analysis, akin to an event-study, allows to

\footnotetext{
${ }^{11}$ A similar approach to assess the degree of exogeneity of the reform has been carried out by Galiani et al. (2005) where they study the effects of water privatization in local jurisdictions in Argentina on child mortality.
} 
produce additional results compared to the main analysis because it deals more formally with the potential reverse causality issue and hints to the dynamics of the effect. In this case I estimate:

$$
Y_{i c t}=\alpha_{i}+\lambda_{t}+\chi_{c t}+\gamma_{i} t+\sum_{\tau=0}^{4} \beta_{-\tau} M u n R e f_{i, t-\tau}+\sum_{\tau=1}^{4} \beta_{+\tau} M u n R e f_{i, t+\tau}+\delta \mathbf{X}_{i c t}+\epsilon_{i c t}
$$

I add to the main specification variables that identify lags and leads of 4 years with respect to the institutional changes. Thus, to reduce the concern on possible anticipatory effect I should find $\sum_{\tau=1}^{4} \beta_{+\tau}$ to be not significantly different from 0 . Differently, I might expect to find posttreatment effect, $\sum_{\tau=0}^{4} \beta_{-\tau}$, to be significantly different from 0 with a negative sign. Further, lagged coefficients define the dynamic of the effect for a relatively short period after the introduction of the referendum. ${ }^{12}$

\section{Results}

\subsection{Main results}

Initial estimates of equation (9) are reported in Table 4. The first three columns show that overall direct democracy at the municipal level negatively affects decentralization, confirming the model's prediction. In the first column I report the results that include a dummy for the presence of the mandatory referendum, municipality fixed effects, year fixed effects and municipal time trends to control for possible different shocks or trends at the municipal level. The results show that decentralization decreases once referendum is introduced. The coefficient suggests a reduction of decentralization of around 1.3 percentage-points. This coefficient is significantly different from zero at $10 \%$. Column (2) highlights that adding to the previous specification time-variant socio-demographic controls does not change neither the size nor the level of significance of the referendum coefficient. Interestingly, among the new covariates only municipal population is significantly different from zero. This might suggest that municipal time trends largely reduce the omitted variable bias, given that they have enough power to control for important time-variant municipal attributes.

In column (3), the coefficient of interest is again negative, but now it turns to be significant at the $99 \%$ confidence level. By adding canton-year fixed effects, I control for any change that happened at the cantonal level over the period considered. The estimated coefficient suggests a reduction of decentralization of 2 percentage-points by the introduction of a referendum at the local level. Basically, the identification here is given by comparing municipalities that change institutions with ones in the same canton that do not change in

\footnotetext{
${ }^{12}$ Ideally, I would have run a more in-depth study on the long term effect by following a formal event-study analysis. However, I believe that with only 45 treated municipalities I would not have produced reliable estimations.
} 
a specific year. I consider this to be the most challenging identification strategy because it takes into account not only the different municipal trends but also actual changes in cantonal task assignments or cantonal availability of direct democracy. This last consideration is of particular interest because it allows me to go a step forward with respect to what has already been done in the literature by Funk and Gathmann (2011) and Feld et al. (2008). I estimate the effect of municipal referendum on decentralization conditional on changes at the cantonal level so that I control for any omitted vertical effects related with the dependent variable.

However, even in my analysis, I am not yet able to asses the whole impact, given the way in which the dependent variable is computed. Indeed, this is mainly affected by changes of municipal expenditures. So, the effect of a municipal mandatory referendum on cantonal expenditure is not directly identified. Nevertheless, theoretically this is expected to make the negative effect of direct democracy on decentralization even larger, given that there could be a substitution in expenditure between municipal and cantonal governments.

For this reason, the last three columns of Table 4 exploit the effect of the reforms on the share of transfers. ${ }^{13}$ These regressions are focused on the revenue side of municipalities. The coefficient of primary interest is negative and significantly different from 0 in all columns. As in the analysis on decentralization, the referendum coefficient does not change from column (4), where additionally to fixed effects I include municipal time trends, to column (5), where I include also time-varying controls. The coefficient of mandatory ref. entails a reduction of the dependent variable of 2.8 percentage-points once a municipality introduces the direct vote on public expenditure. In the last column, the main variable of interest results significant at the $90 \%$ confidence interval level. The introduction of a referendum at the local level decreases the share of expenditure financed through cantonal grants by 2.1 percentage-points when controlling for any change occurred at a cantonal level as well.

These additional results confirm empirically that, by introducing a referendum at the local level, there is a direct effect also on cantonal fiscal decisions. Although the theoretical model does not have predictions for this part of the analysis, the negative coefficient could be coherent with the pattern expected from the theoretical background. Policies promoted by municipalities that introduced referendum are now more transparent for citizens, which entails that their effort to increase the probability of reelection is more "expensive" than before. Thus, cantons rationally reduce transfers to these municipalities, possibly allowing for an increase in their direct expenditure.

\footnotetext{
${ }^{13}$ Here, due to data constraints, the sample takes into accounts 372 municipalities of which 45 are treated and 327 are non treated.
} 


\subsection{Causality}

\subsubsection{Discrete-time duration model}

Table 5 shows the difficulty in finding characteristics that significantly affect the probability of a municipality to introduce a fiscal referendum. Here, I consider only those municipalities that in 1990, the first year of the panel, do not present a fiscal referendum. By following Jenkins (1995), I run a logit model where the dependent variable, mandatory ref., is truncated after the year of introduction of a referendum for those municipalities that reform. All specifications include a fifth-order polynomial to control for duration dependence and errors are clustered at the municipal level.

In column (1) I look mainly at feedback effects from decentralization to the probability of reforming, by including changes in decentralization lagged from 1 to 3 years. These variables do not seem to be correlated with the decision to reform. I add in column (2) the observed time-varying variables already used in the main analysis, considering their first difference. As for decentralization, they do not significantly affect the probability to reform. Finally, I complete the analysis by including several fixed pre-treatment municipal characteristics. Once again, they are not generally able to explain reform decisions. Only the share of inactive population is correlated with a lower probability of reform.

Interestingly, none of the time-varying variables reaches satisfying levels of significance. This seems to be true also for almost the totality of the fixed controls. To some degree, this analysis reduces the concern about potential correlation between control variables and the decision to reform. Importantly, if considered from a different perspective, this result suggests that it is less likely that the decision to reform is correlated with unobserved timevarying characteristics, given that it is already uncorrelated with the observable ones.

\subsubsection{Selection on unobservables.}

The last two rows of Table 6 report significant information about the potential effect of the omitted variable bias on my estimates. ${ }^{14}$ The controlled regressions in column (2), (3) and (4) of Table 6 replicate respectively the specification of column (1), (2) and (3) of Table 4, while the uncontrolled regression includes as covariates only mandatory ref. and municipal fixed effects. By having municipal fixed effects in the uncontrolled regression, I implicitly get rid of a portion of the omitted variable bias that would rely on time invariant heterogeneity among municipalities.

The second last row shows the value of $\delta$ (i.e., the degree of proportionality) such that the estimated coefficient of mandatory ref. is 0 . I assume $R_{\max }=1$. Interestingly, all columns report $\delta>1$. It ranges from a value of 1.25 in column (2) to a value of 28.29 in column (4). This test suggests that, by taking into account my preferred specification in

\footnotetext{
${ }^{14}$ For further details and a formal derivation of $\delta$ and of the identification set see Oster (2014). All calculations are made using PSACALC stata module by Oster (2013).
} 
column (4), selection on unobservables has to be at least 28 time stronger than selection on observables to invalidate the results. Therefore, it is unlikely that the effect of referendum on decentralization is mainly due to unobservables.

The last row gives a further validation to my main analysis by providing identification sets which give bounds to the different estimated coefficients. Here I assume an equal level of proportionality between observables and unobservables selection (i.e., $\delta=1$ ), and again $R_{\max }=1$. None of the estimated sets include positive values. Interestingly, the preferred specification has a very limited identification set which largely confirms a reduction of decentralization due to the introduction of a referendum of about 2 percentage-points.

\subsubsection{Granger causality and dynamics}

The estimation of Equation 10 is reported in Table 7. The first two terms are in the order the sum of the lag coefficients and the sum of the lead coefficients. Interestingly, the latter is not significant in any specification, meaning that we can rule out concerns about reverse causality. Moreover, the inclusion of cantonal-year fixed effects, shown in column (3), reveals that post-treatment effects are negative and significantly different from 0 , as one might expect. Although this result does not challenge directly the potential endogeneity issue, it emphasizes the direction of the effect: the institutional variation comes before the change in the level of decentralization.

Figure 2 gives more information on the pattern of the effects by showing the estimated coefficients of lags and leads, and their confidence intervals. Apart from the second year before the change, all coefficients are negative. However, just the lags are significantly negative. Moreover, the largest jump of decentralization appears the year of change. A further reduction arrives the first year after the reform, while from the second year there is a stabilization of the negative effect. In conclusion, the introduction of the referendum affects decentralization not only in the year of change: indeed, it seems to be present up to 4 years after the reform.

\section{Sensitivity analysis}

The results from my main analysis are all based on a difference in differences analysis, which denotes a comparison between a control and a relatively small treated group. Hence, two further aspects need to be checked to confirm the robustness of my results: the control group's composition and the presence of outliers in the treatment group. On the one hand, although I control for several characteristics and include different fixed effects, the composition of the control group matters in defining the effect of direct democracy. On the other hand, as already noted, the results of this analysis are mainly identified by 45 municipalities which modified the provision of direct democratic instruments. Therefore, it is important to check whether only a few of these municipalities drive the overall results. In this section 
I provide a series of robustness checks challenging the two issues just mentioned. Table 8 shows estimations based on the preferred specification, column (3) of Table 4.

In the first three columns I deal with the fact that the treated group is mainly composed by small municipalities while in the control group also the largest ones are included. I reduce the sample conditional on municipal's size: column (1) considers municipalities with a population lower than 20,000, column (2) population lower than 10,000 and column (3) population lower than 5,000. Again the main coefficient is negative and significant in all specification. The effect is still around -2 percentage-points. In column (4), I consider observations only from the treated group. This fixed effects model estimates differences in the outcome before and after the treatment. Is important to note that in this way I leave out potential selection bias driven by the control group composition by identifying an average treatment effect on the treated. Once again, the negative effect of a mandatory referendum on expenditure decentralization is confirmed and it decreases decentralization by 1.9 percentage-points.

In column (5) and (6) I show two different regressions assessing the potential presence of outliers in the treatment group. ${ }^{15}$ They both present results of the main specification by excluding from the analysis those municipalities showing anomalies in the residuals.

Column (5) excludes the municipalities of Wildberg (index 182) and Emmetten (index 1504). This decision is driven by a first graphical analysis of Figure 3: it presents a scatter graph in which the $\mathrm{Y}$ axis reports the residual of the preferred specification by excluding the dummy variable mandatory ref., while the $\mathrm{X}$ axis measures the residual from a regression in which mandatory ref. is the dependent variable and the regressors are the same as the main specification. This graph allows me to focus on the relationship between decentralization and the mandatory referendum excluding the other variables. The mentioned municipalities show observations that behave unusually and that affect the slope of the line representing the coefficient. In coherence with previous results, the coefficient for mandatory ref. is still negative and significantly different from 0 at the $99 \%$ confidence interval. However, it increases from -0.020 of the main analysis to -0.014 .

In column (6) I go further with respect to the graphical observation by removing all those municipalities that present, for at least one year, a studentized residual with absolute value higher than $3{ }^{16}$ This means that I drop 8 treated municipalities, two of which are the ones already excluded. Although mandatory ref. coefficient is still significant and with negative sign, it increases a little to -0.013 .

As a final test, similarly to Lovenheim and Owens (2014), I run a simple permutation test

\footnotetext{
${ }^{15}$ This robustness check is also a way to compensate for possible mistakes in the reported information on municipal public expenditure in the survey conducted by the Swiss Ministry of Finance.

${ }^{16}$ Studentized residuals are residuals corrected for their standard errors. They can be described as the $t$ statistic which would have a dummy variable on whether that specific observation would be included in the regression or not. Thus, by assuming 3 as threshold, I implicitly exclude those observations for which the dummy is significant at the $1 \%$ level (Belsley et al., 1980).
} 
where I regress my main specification 45 times removing each time a treated municipality. ${ }^{17}$ Each estimation reports a negative and significant coefficient for the dummy on municipal referendum. The value ranges between -0.021 and $-0.015 .{ }^{18}$ This test confirms that there is not a single municipality that defines the whole effect.

Summing up, these results seem to add support to the expected negative effect of local direct democratic institutions on decentralization.

\section{Conclusion and discussion}

In this analysis I show that direct democracy affects decentralization of expenditure in a different way than a pure representative democracy would.

From a theoretical perspective, I emphasize how direct democracy can work as an information tool that makes governments decisions more transparent and how this affects expenditure decentralization. When two or more levels of governments jointly provide a public good, they become mutually responsible from a citizen's point of view. Thus, politicians from different levels who aim to be reelected have similar objective functions. To maximize their probabilities of being in charge again the next period, they find it convenient to move expenditure to the level where the control of citizens is the lowest (i.e., representative democracy) such that any electoral claims about the goodness of their activities is difficult to verify. Therefore, the model predicts that decentralization should increase if direct democracy is introduced at the cantonal level, while it should decrease if direct democracy is introduced at the local level.

I empirically test the second point of the prediction by using a newly assembled dataset which considers a sample of 406 Swiss municipalities over a period of 20 years. In this sample 45 municipalities either introduced or abolished a mandatory referendum on new expenditure. Thanks to these changes over time, I can use a difference in differences approach confirming that decentralization, decreases once a municipality strengthens citizen's participation. By using a number of strategies I importantly reduce the concern about the potential omitted variable bias so that I can suggest a causal interpretation of the results. First, I show that the decision to reform taken by municipalities is not correlated with timevarying variables. Second, I evaluate that in order to invalidate the effect of referendum on decentralization, selection based on unobservables has to be extremely bigger than selection on observables. Finally, I do not find any anticipatory effects while posttreatment effect are present and coherent with the finding of the main analysis. As developed out from Funk and Gathmann (2011) and Feld et al. (2008), given my main focus on municipalities instead of cantons, the results are robust to changes that might have occurred at all levels of gov-

\footnotetext{
${ }^{17}$ Lovenheim and Owens (2014) test how public aids limitation to students convicted for drug offenses affects their education achievements. Interestingly, they deal with a small treated group composed by 46 students.

${ }^{18}$ Detailed results are displayed in Table 9.
} 
ernment (i.e., municipalities and cantons) either in terms of task assignments or availability of direct legislation instrument.

I estimate a reduction of 2 percentage-points of decentralization, which calculated at the mean suggests a decrease of decentralization of about $5 \%$. To produce a numerical result, let us assume that the introduction of the mandatory referendum makes expenditure move from the municipal to the cantonal level, with no effect on the total amount of expenditure. On average a municipality from the sample spends around 4,600 CHF and a canton 8,000 CHF per capita. Therefore, as a pure speculative consequence, the introduction of a mandatory referendum on new expenditure would decrease the per capita local expenditure of 700 CHF with a respective increase in the cantonal one. To put it differently, that would suggest a reduction of expenditure at the municipal level of nearly $15 \%$. The empirical estimation suggests that the same effect would occur if, holding other characteristics fixed, the population in a municipality decreases by about $10 \%$.

Additionally, the paper discovers that direct democracy seems to affect negatively and significantly the amount of local expenditure funded at the cantonal level. This point highlights again the presence of a vertical interaction between decision making processes and policy decisions.

Finally, I believe, regardless of the main objective of the research, these findings make clear that studies on federations need a more thorough examination of conditions that does not solely refer to the level of government in analysis. Vertical interactions between governments significantly affect public policies. By omitting from the analysis characteristics of other level jurisdictions might limit the overall reliability of the results. 


\section{Location of municipalities in the sample}

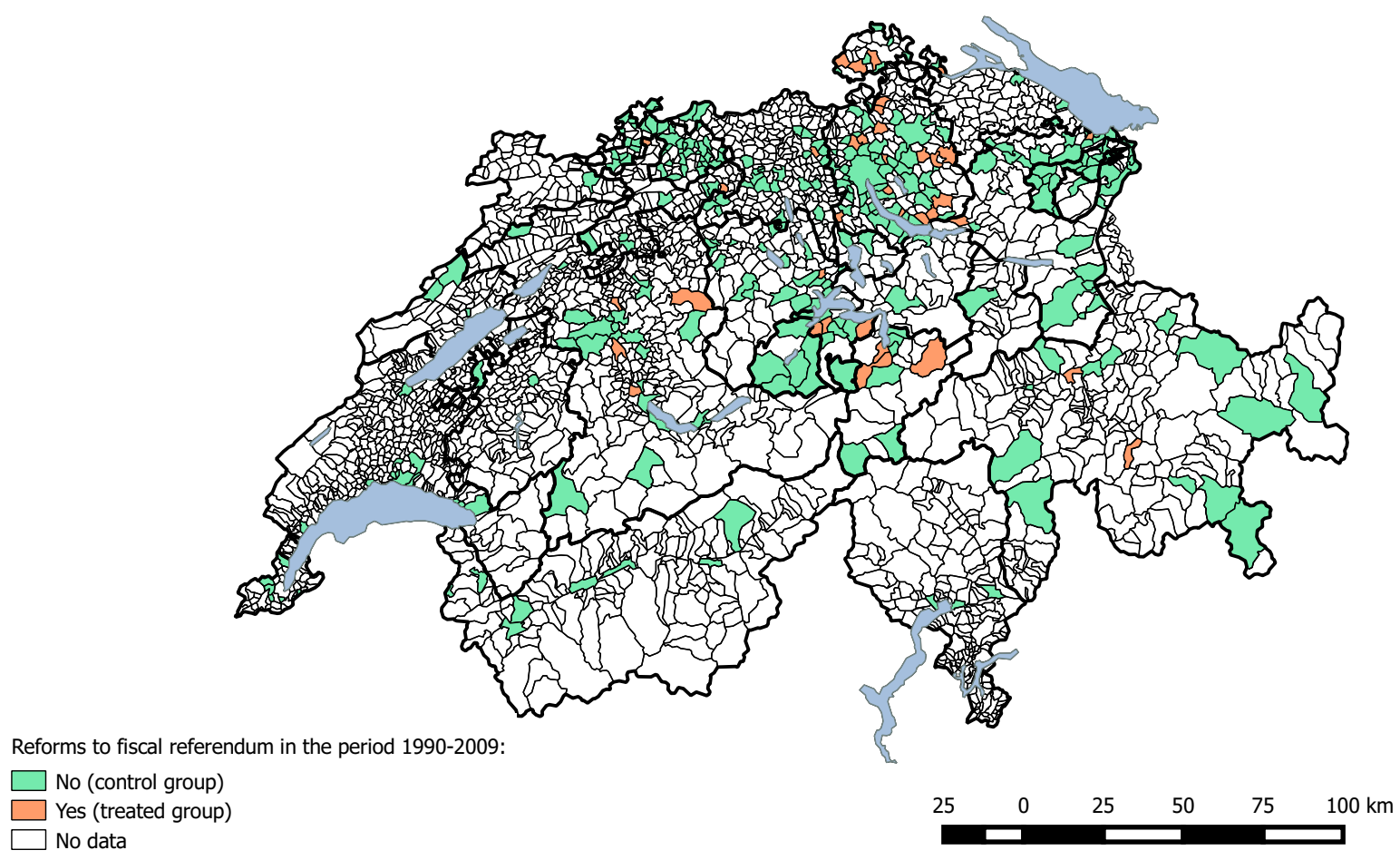

Figure 1: Location of municipalities in the sample. 


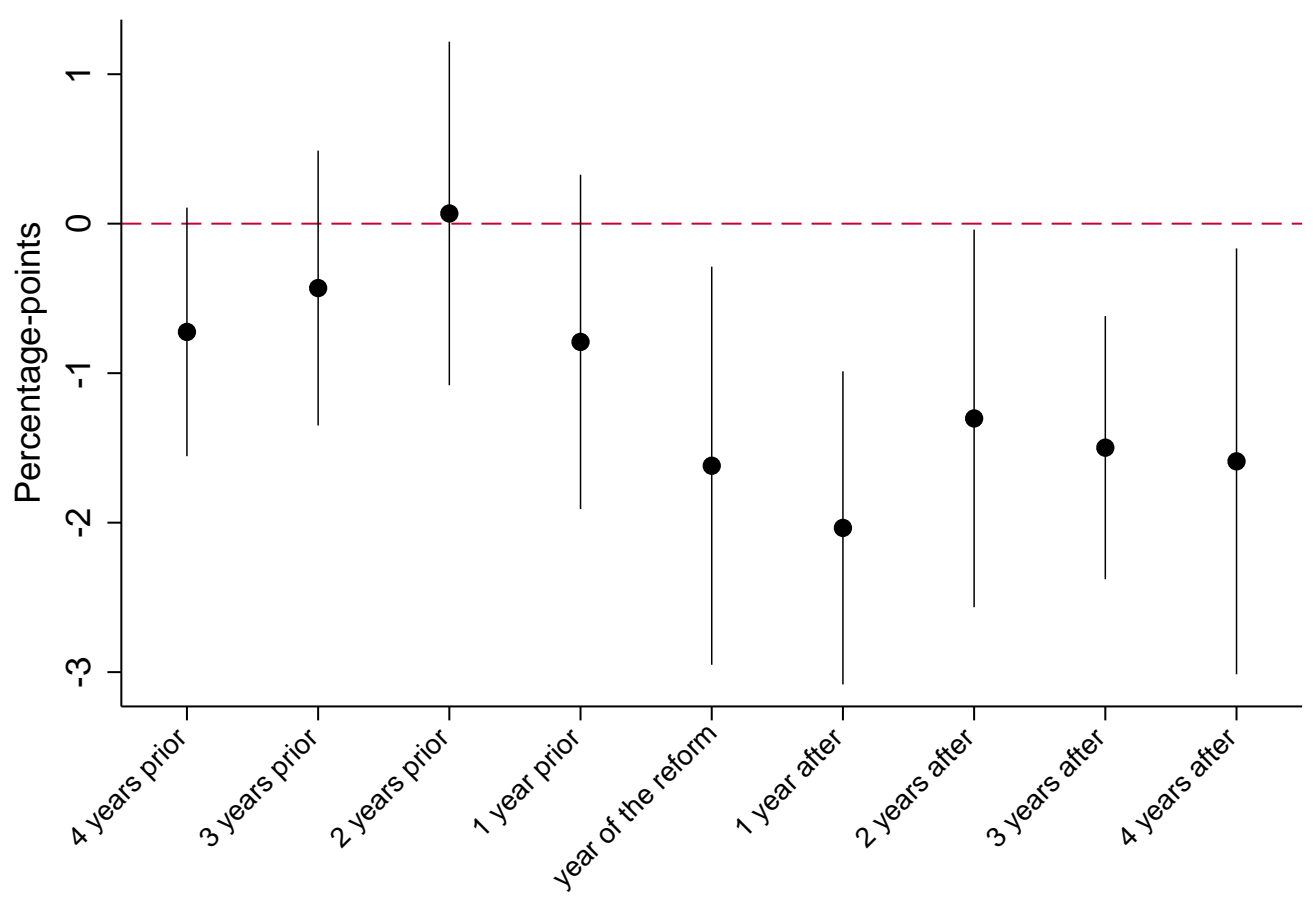

Time relative to the introduction of a mandatory referendum

Figure 2: Leads and Lags coefficients. 


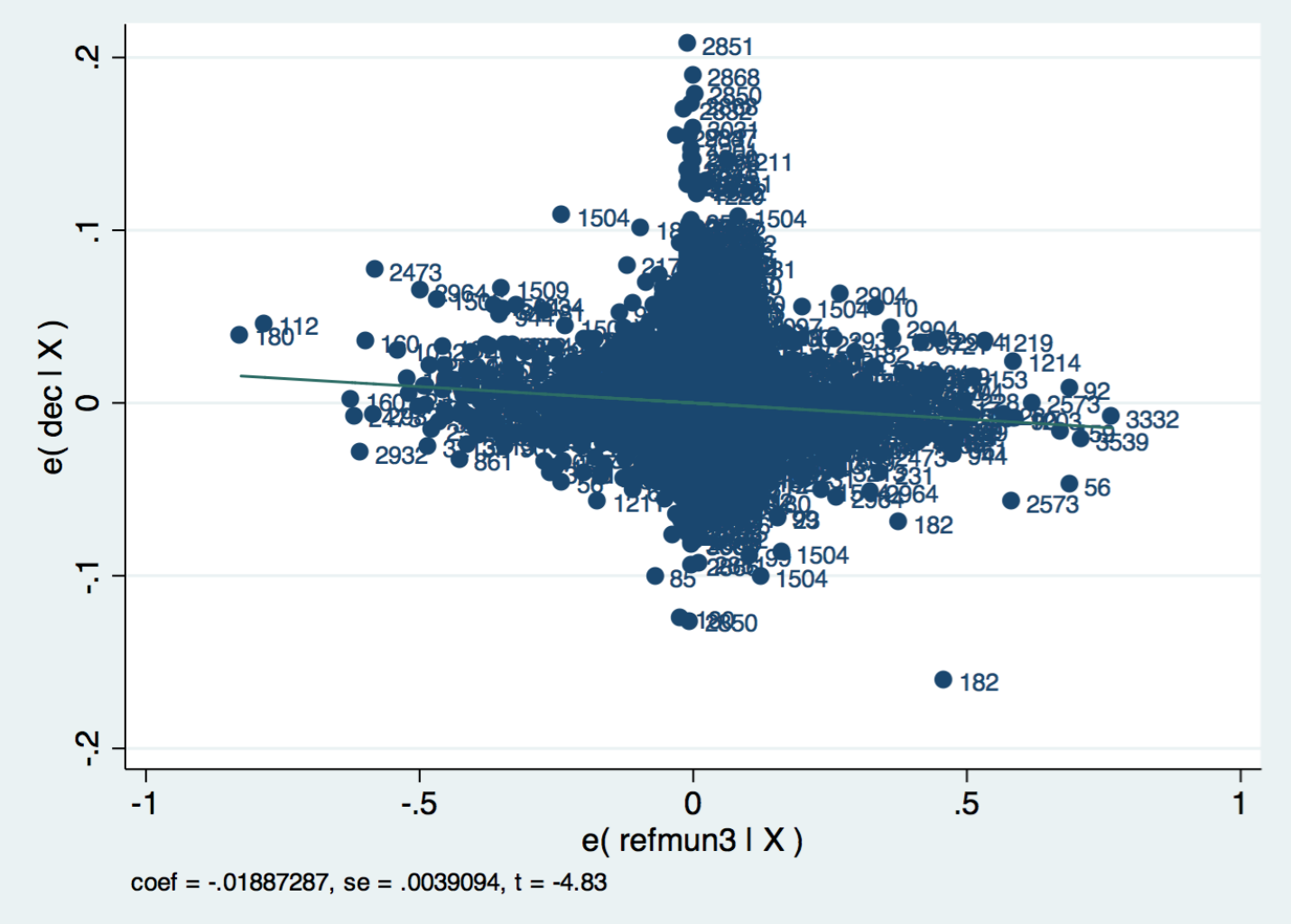

Figure 3: Outliers - AVplot. 
Table 1: Destination of public expenditure by level of government in percentage, 2009

\begin{tabular}{lrr}
\hline & Cantons & Municipalities \\
\hline Administration & $44 \%$ & $56 \%$ \\
Security & $71 \%$ & $29 \%$ \\
Education & $63 \%$ & $37 \%$ \\
Culture & $34 \%$ & $66 \%$ \\
Health & $87 \%$ & $13 \%$ \\
Welfare & $61 \%$ & $39 \%$ \\
Transport & $57 \%$ & $43 \%$ \\
Environment & $22 \%$ & $78 \%$ \\
Economy & $72 \%$ & $28 \%$ \\
\hline Total & $60 \%$ & $40 \%$ \\
\hline
\end{tabular}

Source: Swiss Federal Department of Finance 
Table 2: Sample details

\begin{tabular}{|c|c|c|c|c|}
\hline Canton & Abbreviation & $\begin{array}{l}\text { N. of } \\
\text { municipalities } \\
\text { in the sample }\end{array}$ & $\begin{array}{l}\text { N. of } \\
\text { municipal } \\
\text { reforms }\end{array}$ & $\begin{array}{l}\text { Cantonal level } \\
\text { reforms (year) }\end{array}$ \\
\hline Aargau & $\mathrm{AG}$ & 28 & 1 & Yes (2003) \\
\hline Appenzell Ausserrhoden & $\mathrm{AR}$ & 17 & 0 & No \\
\hline Appenzell Innerrhoden & AI & 3 & 0 & No \\
\hline Basel-Landschaft & $\mathrm{BL}$ & 59 & 0 & No \\
\hline Basel-Stadt & BS & 2 & 0 & No \\
\hline Bern & $\mathrm{BE}$ & 34 & 5 & Yes (1993) \\
\hline Fribourg & FR & 1 & 0 & No \\
\hline Geneva & GE & 8 & 0 & No \\
\hline Glarus & GL & 1 & 0 & No \\
\hline Graubünden & GR & 19 & 2 & No \\
\hline Jura & $\mathrm{JU}$ & 2 & 0 & No \\
\hline Lucerne & $\mathrm{LU}$ & 35 & 2 & No \\
\hline Neuchâtel & $\mathrm{NE}$ & 6 & 0 & Yes (2002) \\
\hline Nidwalden & NW & 9 & 3 & No \\
\hline Obwalden & OW & 7 & 0 & Yes (1999) \\
\hline Schaffhausen & $\mathrm{SH}$ & 15 & 4 & No \\
\hline Schwyz & $\mathrm{SZ}$ & 3 & 0 & No \\
\hline Solothurn & $\mathrm{SO}$ & 9 & 2 & No \\
\hline St. Gallen & $\mathrm{SG}$ & 34 & 2 & No \\
\hline Thurgau & $\mathrm{TG}$ & 2 & 0 & No \\
\hline Ticino & $\mathrm{TI}$ & 2 & 0 & No \\
\hline Uri & UR & 14 & 3 & No \\
\hline Valais & VS & 7 & 0 & Yes (1994) \\
\hline Vaud & $\mathrm{VD}$ & 11 & 0 & Yes (1999-2004) \\
\hline Zug & $\mathrm{ZG}$ & 4 & 0 & No \\
\hline Zürich & $\mathrm{ZH}$ & 74 & 21 & Yes (1999) \\
\hline TOT & - & 406 & 45 & 7 \\
\hline
\end{tabular}


Table 3: Summary statistics

\begin{tabular}{lccccc}
\hline \multicolumn{1}{c}{ Variable } & Mean & Std. Dev. & Min. & Max. & N \\
\hline Dependent variable & & & & & \\
Expenditure Decentralization p/c & 0.367 & 0.089 & 0.077 & 0.651 & 6646 \\
Share of transfers & 0.099 & 0.081 & 0 & 1 & 4305 \\
Independent variables & & & & & \\
Mandatory ref. & 0.515 & 0.5 & 0 & 1 & 6646 \\
Population (Log) & 8.52 & 1.179 & 4.522 & 12.818 & 6646 \\
Share pop foreigner & 0.165 & 0.094 & 0 & 0.527 & 6646 \\
Dependency ratio & 0.63 & 0.083 & 0.375 & 1.002 & 6646 \\
Left wing & 0.259 & 0.121 & 0 & 0.896 & 6619 \\
Turnout & 0.448 & 0.092 & 0.146 & 0.817 & 6619 \\
Discrete-time Hazard model & & & & & \\
Area & 17.327 & 26.574 & 1.3 & 203.9 & 2577 \\
Urban & 0.579 & 0.494 & 0 & 1 & 2577 \\
Urban center & 0.107 & 0.31 & 0 & 1 & 2577 \\
Touristic center & 0.025 & 0.157 & 0 & 1 & 2577 \\
Lake & 0.246 & 0.431 & 0 & 1 & 2577 \\
Share pop German speaker & 72.745 & 33.375 & 0.729 & 100 & 2577 \\
Share pop primary sector & 5.689 & 6.487 & 0.26 & 34.043 & 2577 \\
Share pop inactive & 1.997 & 1.122 & 0 & 6.383 & 2577 \\
Share pop university degree & 11.905 & 4.452 & 2.355 & 27.298 & 2577 \\
Share pop protestant & 42.788 & 24.587 & 0.594 & 88.116 & 2577 \\
\hline & & & & &
\end{tabular}


Table 4: Impact of fiscal referendum on decentralization

\begin{tabular}{|c|c|c|c|c|c|c|}
\hline & \multicolumn{3}{|c|}{ Decetralization } & \multicolumn{3}{|c|}{ Share of transfers } \\
\hline & $(1)$ & $(2)$ & $(3)$ & $(4)$ & $(5)$ & (6) \\
\hline \multirow[t]{2}{*}{ Mandatory ref. } & $-0.013^{*}$ & $-0.013^{*}$ & $-0.020 * * *$ & $-0.028 * *$ & $-0.028 * *$ & $-0.021 *$ \\
\hline & $(0.007)$ & $(0.007)$ & $(0.006)$ & $(0.013)$ & $(0.013)$ & $(0.011)$ \\
\hline \multirow[t]{2}{*}{ Population (Log) } & & $-0.170 * * *$ & $-0.215^{* * *}$ & & 0.000 & 0.048 \\
\hline & & $(0.040)$ & $(0.044)$ & & $(0.074)$ & $(0.077)$ \\
\hline \multirow[t]{2}{*}{ Share pop foreigner } & & 0.012 & -0.041 & & $0.439^{*}$ & 0.135 \\
\hline & & $(0.077)$ & $(0.064)$ & & $(0.228)$ & $(0.188)$ \\
\hline \multirow[t]{2}{*}{ Dependency ratio } & & -0.047 & 0.002 & & 0.038 & -0.065 \\
\hline & & $(0.079)$ & $(0.073)$ & & $(0.166)$ & $(0.149)$ \\
\hline \multirow[t]{2}{*}{ Left wing } & & -0.019 & 0.002 & & 0.036 & $-0.147^{* *}$ \\
\hline & & $(0.016)$ & $(0.031)$ & & $(0.063)$ & $(0.067)$ \\
\hline \multirow[t]{2}{*}{ Turnout } & & -0.010 & $0.064^{* *}$ & & -0.051 & 0.007 \\
\hline & & $(0.024)$ & $(0.026)$ & & $(0.045)$ & $(0.066)$ \\
\hline Year FE & Yes & Yes & Yes & Yes & Yes & Yes \\
\hline Municipality FE & Yes & Yes & Yes & Yes & Yes & Yes \\
\hline Municipality $\times$ time trend & Yes & Yes & Yes & Yes & Yes & Yes \\
\hline Canton $\times$ year fixed effects & No & No & Yes & No & No & Yes \\
\hline $\mathrm{R}^{2}$ & 0.900 & 0.902 & 0.921 & 0.707 & 0.709 & 0.809 \\
\hline $\mathrm{N}$ & 6646 & 6619 & 6619 & 4289 & 4270 & 4270 \\
\hline
\end{tabular}

Notes: In columns (1) to (3) the dependent variable is decentralization which is calculated as municipal share of cantonal and municipal expenditures. In columns (4) to (6) the dependent variable is Share of transfers which is calculated as cantonal transfers share of municipal expenditures. Standard errors in parenthesis. Standard errors clustered two ways by municipality and by year. ${ }^{*} \mathrm{p}<0.1,{ }^{* *} \mathrm{p}<0.05$ and ${ }^{* * *} \mathrm{p}<0.01$. 
Table 5: Discrete-time hazard estimation of the probability to introduce referendum

\begin{tabular}{|c|c|c|c|}
\hline & (1) & (2) & (3) \\
\hline \multicolumn{4}{|l|}{ Time-varying variables } \\
\hline \multirow[t]{2}{*}{$\Delta$ Decentralization $_{t-1}$} & -8.373 & -8.402 & -7.027 \\
\hline & $(11.737)$ & $(11.295)$ & $(10.378)$ \\
\hline \multirow[t]{2}{*}{$\Delta$ Decentralization $_{t-2}$} & -0.345 & 0.045 & -0.670 \\
\hline & $(10.407)$ & $(9.990)$ & $(9.842)$ \\
\hline \multirow[t]{2}{*}{$\Delta$ Decentralization $_{t-3}$} & 2.774 & 2.467 & 2.746 \\
\hline & $(3.847)$ & $(3.695)$ & $(3.698)$ \\
\hline \multirow[t]{2}{*}{$\Delta$ Population $_{t-1}(\mathrm{Log})$} & & -1.231 & -1.325 \\
\hline & & $(6.691)$ & $(6.987)$ \\
\hline \multirow[t]{2}{*}{$\Delta$ Share pop foreigner $_{t-1}$} & & 1.368 & 0.625 \\
\hline & & $(20.348)$ & $(20.867)$ \\
\hline \multirow[t]{2}{*}{$\Delta$ Dependency ratio $t-1$} & & -33.631 & -31.828 \\
\hline & & $(23.624)$ & $(29.233)$ \\
\hline \multirow[t]{2}{*}{$\Delta$ Left wing $t-1$} & & -6.590 & -8.140 \\
\hline & & $(4.896)$ & $(5.505)$ \\
\hline \multirow{2}{*}{$\Delta$ Turnout $_{t-1}$} & & 0.028 & 0.034 \\
\hline & & $(0.030)$ & $(0.034)$ \\
\hline \multicolumn{4}{|l|}{ Fixed pre-treatment variables (1990) } \\
\hline \multirow[t]{2}{*}{ Area (mun) } & & & 0.002 \\
\hline & & & $(0.010)$ \\
\hline \multirow[t]{2}{*}{ Urban (mun) } & & & -0.061 \\
\hline & & & $(0.530)$ \\
\hline \multirow[t]{2}{*}{ Urban center dummy (mun) } & & & 1.036 \\
\hline & & & $(1.411)$ \\
\hline \multirow[t]{2}{*}{ Turistic (mun) } & & & 0.553 \\
\hline & & & $(1.175)$ \\
\hline \multirow[t]{2}{*}{ Lake (mun) } & & & 0.082 \\
\hline & & & $(0.622)$ \\
\hline \multirow[t]{2}{*}{ Share pop. German speakers (mun) } & & & 0.018 \\
\hline & & & $(0.016)$ \\
\hline \multirow[t]{2}{*}{ Share pop. employed in the primary sector } & & & -0.034 \\
\hline & & & $(0.038)$ \\
\hline \multirow[t]{2}{*}{ Share pop. inactive } & & & $-1.058^{* * *}$ \\
\hline & & & $(0.296)$ \\
\hline \multirow[t]{2}{*}{ Share pop. university degree } & & & 0.091 \\
\hline & & & $(0.068)$ \\
\hline \multirow[t]{3}{*}{ Share pop. protestant } & & & 0.003 \\
\hline & & & $(0.009)$ \\
\hline & 2594 & 2594 & 2577 \\
\hline
\end{tabular}

Notes: The dependent variable is mandatory (ref). A fifth-order polynomial is used to control for duration dependence. Standard errors in parenthesis. Standard errors clustered by municipality. ${ }^{*} \mathrm{p}<0.1,{ }^{* *} \mathrm{p}<0.05$ and ${ }^{* * *} \mathrm{p}<0.01$. 
Table 6: Selection on unobservables

\begin{tabular}{lcccc}
\hline & $(1)$ & $(2)$ & $(3)$ & $(4)$ \\
& Uncontrolled & Controlled & Controlled & Controlled \\
\hline Coefficient & -0.02083 & -0.01322 & -0.01347 & -0.02030 \\
R-squared & 0.825 & 0.900 & 0.902 & 0.921 \\
\hline$\delta$ & & 1.25 & 1.36 & 28.29 \\
Identified Set & & {$[-0.01322,-0.00305]$} & {$[-0.01347,-0.00412]$} & {$[-0.02030,-0.01986]$} \\
\hline
\end{tabular}

Notes: The dependent variable is decentralization. The reported coefficients are those of mandatory ref.. The uncontrolled regression includes only municipality fixed effects. The controlled regressions recall the specifications from column (1) to (3) of Table 4. $\delta$ is calculated assuming $R_{\max }=1$ and $\beta=0$. The identified set is calculated assuming $R_{\max }=1$ and $\delta=1$. 
Table 7: Impact of fiscal referendum on decentralization with Leads and Lags

\begin{tabular}{|c|c|c|c|}
\hline & (1) & $(2)$ & $(3)$ \\
\hline \multirow[t]{2}{*}{ Mandatory ref. $\sum_{\tau=0}^{4} \beta_{-\tau}$} & -0.033 & -0.039 & $-0.080 * * *$ \\
\hline & $(0.031)$ & $(0.031)$ & $(0.026)$ \\
\hline \multirow[t]{2}{*}{ Mandatory ref. $\sum_{\tau=1}^{4} \beta_{\tau}$} & 0.004 & 0.000 & -0.019 \\
\hline & $(0.021)$ & $(0.020)$ & $(0.017)$ \\
\hline \multirow[t]{2}{*}{ Population (Log) } & & $-0.171 * * *$ & $-0.217 * * *$ \\
\hline & & $(0.041)$ & $(0.044)$ \\
\hline \multirow[t]{2}{*}{ Share pop foreigner } & & 0.013 & -0.036 \\
\hline & & $(0.077)$ & $(0.065)$ \\
\hline \multirow[t]{2}{*}{ Dependency ratio } & & -0.045 & 0.010 \\
\hline & & $(0.079)$ & $(0.073)$ \\
\hline \multirow[t]{2}{*}{ Left wing } & & -0.019 & 0.001 \\
\hline & & $(0.016)$ & $(0.031)$ \\
\hline \multirow[t]{2}{*}{ Turnout } & & -0.010 & $0.063^{* *}$ \\
\hline & & $(0.024)$ & $(0.026)$ \\
\hline Year FE & Yes & Yes & Yes \\
\hline Municipality FE & Yes & Yes & Yes \\
\hline Municipality $\times$ time trend & Yes & Yes & Yes \\
\hline Canton $\times$ year fixed effects & No & No & Yes \\
\hline $\mathrm{R}^{2}$ & 0.900 & 0.902 & 0.921 \\
\hline $\mathrm{N}$ & 6646 & 6619 & 6619 \\
\hline
\end{tabular}

Notes: The dependent variable is decentralization which is calculated as municipal share of cantonal and municipal expenditures. Standard errors in parenthesis. Standard errors clustered two ways by municipality and by year. ${ }^{*} \mathrm{p}<0.1,{ }^{* *} \mathrm{p}<0.05$ and ${ }^{* * *} \mathrm{p}<0.01$. 
Table 8: Sensitivity analysis

\begin{tabular}{|c|c|c|c|c|c|c|}
\hline & $(1)$ & $(2)$ & (3) & $(4)$ & $(5)$ & (6) \\
\hline Mandatory ref. & $\begin{array}{c}-0.021^{* * *} \\
(0.006)\end{array}$ & $\begin{array}{c}-0.023^{* * *} \\
(0.006)\end{array}$ & $\begin{array}{l}-0.018^{*} \\
(0.010)\end{array}$ & $\begin{array}{c}-0.019 \text { *** } \\
(0.006)\end{array}$ & $\begin{array}{c}-0.014^{* * *} \\
(0.005)\end{array}$ & $\begin{array}{c}-0.013^{* *} \\
(0.006)\end{array}$ \\
\hline Population (Log) & $\begin{array}{c}-0.214^{* * *} \\
(0.046)\end{array}$ & $\begin{array}{c}-0.202^{* * *} \\
(0.050)\end{array}$ & $\begin{array}{c}-0.220^{* * *} \\
(0.067)\end{array}$ & $\begin{array}{l}-0.082 \\
(0.080)\end{array}$ & $\begin{array}{c}-0.227^{* * *} \\
(0.044)\end{array}$ & $\begin{array}{c}-0.231^{* * *} \\
(0.045)\end{array}$ \\
\hline Share pop foreigner & $\begin{array}{l}-0.056 \\
(0.068)\end{array}$ & $\begin{array}{l}-0.085 \\
(0.069)\end{array}$ & $\begin{array}{l}-0.069 \\
(0.083)\end{array}$ & $\begin{array}{c}0.096 \\
(0.195)\end{array}$ & $\begin{array}{l}-0.055 \\
(0.065)\end{array}$ & $\begin{array}{l}-0.059 \\
(0.066)\end{array}$ \\
\hline Dependency ratio & $\begin{array}{l}-0.007 \\
(0.074)\end{array}$ & $\begin{array}{l}-0.008 \\
(0.080)\end{array}$ & $\begin{array}{l}-0.029 \\
(0.087)\end{array}$ & $\begin{array}{l}-0.178 \\
(0.262)\end{array}$ & $\begin{array}{c}0.005 \\
(0.073)\end{array}$ & $\begin{array}{c}0.011 \\
(0.068)\end{array}$ \\
\hline Left wing & $\begin{array}{c}0.000 \\
(0.032)\end{array}$ & $\begin{array}{c}0.008 \\
(0.034)\end{array}$ & $\begin{array}{c}0.038 \\
(0.040)\end{array}$ & $\begin{array}{c}0.041 \\
(0.126)\end{array}$ & $\begin{array}{c}0.005 \\
(0.031)\end{array}$ & $\begin{array}{c}0.007 \\
(0.030)\end{array}$ \\
\hline Turnout & $\begin{array}{c}0.061^{* *} \\
(0.026)\end{array}$ & $\begin{array}{c}0.062^{* *} \\
(0.028)\end{array}$ & $\begin{array}{c}0.056 \\
(0.036)\end{array}$ & $\begin{array}{l}-0.034 \\
(0.090)\end{array}$ & $\begin{array}{c}0.074^{* * *} \\
(0.024)\end{array}$ & $\begin{array}{c}0.071^{* * *} \\
(0.024)\end{array}$ \\
\hline Year FE & Yes & Yes & Yes & Yes & Yes & Yes \\
\hline Municipality FE & Yes & Yes & Yes & Yes & Yes & Yes \\
\hline Municipality $\times$ time trend & Yes & Yes & Yes & Yes & Yes & Yes \\
\hline Canton $\times$ year fixed effects & Yes & Yes & Yes & Yes & Yes & Yes \\
\hline $\mathrm{R}^{2}$ & 0.908 & 0.885 & 0.864 & 0.909 & 0.924 & 0.925 \\
\hline $\mathrm{N}$ & 6060 & 4551 & 2633 & 798 & 6581 & 6475 \\
\hline
\end{tabular}

Notes: The dependent variable is decentralization which is calculated as municipal share of cantonal and municipal expenditures. Column (1) considers municipalities with less than 20,000 inhabitants, column (2) considers municipalities with less than 10,000 inhabitants and column (3) considers municipalities with less than 5,000 inhabitants. Column (4) includes treated municipalities. Column (5) considers all municipalities but Wildberg (index 182) and Emmetten (index 1504) while column (6) considers all municipalities but the treated ones with a studentized residual with absolute value higher than 3 for at least one year. Standard errors in parenthesis. Standard errors clustered two ways by municipality and by year. Standard errors in parenthesis. Standard errors clustered two ways by municipality and by year. ${ }^{*} \mathrm{p}<0.1$, $* * \mathrm{p}<0.05$ and $* * * \mathrm{p}<0.01$. 
Table 9: Sensitivity analysis - Permutation test

\begin{tabular}{|c|c|c|c|c|c|}
\hline Index Excluded Municipality & Coefficient & Stand. Error & Index Excluded Municipality & Coefficient & Stand. Error \\
\hline 10 & $-0.020 * * *$ & 0.005 & 1099 & $-0.018^{* * *}$ & 0.006 \\
\hline 23 & $-0.019 * * *$ & 0.006 & 1203 & $-0.018^{* * *}$ & 0.005 \\
\hline 28 & $-0.019^{* * *}$ & 0.006 & 1214 & $-0.019^{* * *}$ & 0.005 \\
\hline 54 & $-0.019 * * *$ & 0.006 & 1219 & $-0.020^{* * *}$ & 0.005 \\
\hline 56 & $-0.018^{* * *}$ & 0.006 & 1504 & $-0.016^{* * *}$ & 0.005 \\
\hline 81 & $-0.018^{* * *}$ & 0.006 & 1506 & $-0.018^{* * *}$ & 0.006 \\
\hline 90 & $-0.018^{* * *}$ & 0.006 & 1509 & $-0.018^{* * *}$ & 0.006 \\
\hline 92 & $-0.019 * * *$ & 0.005 & 2473 & $-0.017^{* * *}$ & 0.005 \\
\hline 99 & $-0.018^{* * *}$ & 0.006 & 2573 & $-0.018^{* * *}$ & 0.005 \\
\hline 112 & $-0.018^{* * *}$ & 0.006 & 2904 & $-0.021^{* * *}$ & 0.005 \\
\hline 113 & $-0.018^{* * *}$ & 0.006 & 2932 & $-0.020^{* * *}$ & 0.006 \\
\hline 117 & $-0.019 * * *$ & 0.006 & 2964 & $-0.017^{* * *}$ & 0.005 \\
\hline 151 & $-0.018^{* * *}$ & 0.006 & 2971 & $-0.020^{* * *}$ & 0.005 \\
\hline 153 & $-0.019^{* * *}$ & 0.006 & 3332 & $-0.019 * * *$ & 0.005 \\
\hline 159 & $-0.019 * * *$ & 0.006 & 3539 & $-0.018^{* * *}$ & 0.006 \\
\hline 160 & $-0.018^{* * *}$ & 0.006 & 3721 & $-0.020 * * *$ & 0.005 \\
\hline 180 & $-0.018^{* * *}$ & 0.006 & 4034 & $-0.017^{* * *}$ & 0.005 \\
\hline 182 & $-0.015^{* * *}$ & 0.005 & & & \\
\hline 199 & $-0.019^{* * *}$ & 0.006 & & & \\
\hline 228 & $-0.019 * * *$ & 0.006 & & & \\
\hline 231 & $-0.018^{* * *}$ & 0.006 & & & \\
\hline 551 & $-0.018^{* * *}$ & 0.006 & & & \\
\hline 861 & $-0.019 * * *$ & 0.006 & & & \\
\hline 944 & $-0.018^{* * *}$ & 0.006 & & & \\
\hline 954 & $-0.019 * * *$ & 0.006 & & & \\
\hline 957 & $-0.019 * * *$ & 0.006 & & & \\
\hline 1052 & $-0.018^{* * *}$ & 0.006 & & & \\
\hline
\end{tabular}

Notes: The table reports estimates for the dummy mandatory ref. (mun) where each time a municipality is left out from the sample. The dependent variable is decentralization which is calculated as municipal share of cantonal and municipal expenditures. The independent variable are the same used in column (3) of Table 4. Standard errors in parenthesis. Standard errors clustered two ways by municipality and by year. ${ }^{*} \mathrm{p}<0.1,{ }^{* *} \mathrm{p}<0.05$ and ${ }^{* * *} \mathrm{p}<0.01$. 


\section{References}

Altonji, Joseph G., Todd E. Elder, and Christopher R. Taber (2005) 'Selection on Observed and Unobserved Variables: Assessing the Effectiveness of Catholic Schools.' Journal of Political Economy 113(1), 151-184

Angrist, Joshua David, and Jörn-Steffen Pischke (2009) Mostly harmless econometrics (Princeton, NJ [u.a.]: Princeton Univ. Press)

Belsley, D.A., E. Kuh, and R.E. Welsch (1980) Regression Diagnostics: Identifying Influential Data and Source of Collinearity (New York: John Wiley)

Benz, Matthias, and Alois Stutzer (2007) 'Direct democracy and citizens' information about politics.' In Direct Democracy in Europe, ed. Zoltan Tibor Pallinger, Bruno Kaufmann, Wilfried Marxer, and Theo Schiller (VS Verlag für Sozialwissenschaften) pp. 125-142

Besley, Timothy, and Anne Case (1995) 'Incumbent behavior: Vote-seeking, tax-setting, and yardstick competition.' American Economic Review 85(1), 25-45

Besley, Timothy, and Stephen Coate (2003) 'Centralized versus decentralized provision of local public goods: a political economy approach.' Journal of Public Economics $87(12), 2611-2637$

Bordignon, Massimo, Floriana Cerniglia, and Federico Revelli (2003) 'In search of yardstick competition: a spatial analysis of italian municipality property tax setting.' Journal of Urban Economics 54(2), 199-217

Brülhart, Marius, and Mario Jametti (2006) 'Vertical versus horizontal tax externalities: An empirical test.' Journal of Public Economics 90(10-11), 2027-2062

Bützer, Gebhard (2007) Direkte Demokratie in Schweizer Städten: Ursprung, Ausgestaltung und Gebrauch im Vergleich (Baden-Baden: Nomos.)

Cameron, A. Colin, Jonah B. Gelbach, and Douglas L. Miller (2011) 'Robust Inference With Multiway Clustering.' Journal of Business 83 Economic Statistics 29(2), 238-249

Feld, Lars P., and John G. Matsusaka (2003) 'Budget referendums and government spending: evidence from swiss cantons.' Journal of Public Economics 87(12), 2703-2724

Feld, Lars P., Christoph A. Schaltegger, and Jan Schnellenbach (2008) 'On government centralization and fiscal referendums.' European Economic Review 52(4), 611-645

Funk, Patricia, and Christina Gathmann (2011) 'Does direct democracy reduce the size of government? new evidence from historical data, 1890 - 2000.' Economic Journal 121(557), 1252-1280 
Funk, Patricia, and Christina Gathmann (2013) 'Voter preferences, direct democracy and government spending.' European Journal of Political Economy 32(C), 300-319

Galiani, Sebastian, Paul Gertler, and Ernesto Schargrodsky (2005) 'Water for Life: The Impact of the Privatization of Water Services on Child Mortality.' Journal of Political Economy 113(1), 83-120

Galletta, Sergio, and Mario Jametti (2012) 'How to tame two leviathans? revisiting the effect of direct democracy on local public expenditure.' CESifo Working Paper Series, CESifo Group Munich, Nov

Gerber, Elisabeth R. (1996) 'Legislative response to the threat of popular initiatives.' American Journal of Political Science 40(1), pp. 99-128

Granger, C W J (1969) 'Investigating causal relations by econometric models and crossspectral methods.' Econometrica 37(3), 424-38

Hinnerich, Björn Tyrefors, and Per Pettersson-Lidbom (2014) 'Democracy, redistribution, and political participation: Evidence from sweden 1919-1938.' Econometrica 82(3), 961993

Jametti, Mario, and Marcelin Joanis (2011) 'Electoral competition as a determinant of fiscal decentralization.' CESifo Working Paper Series 3574, CESifo Group Munich

- (2014) 'Elections and de facto Expenditure Decentralization in Canada.' CESifo Working Paper Series 4791, CESifo Group Munich

Jenkins, Stephen P (1995) 'Easy Estimation Methods for Discrete-Time Duration Models.' Oxford Bulletin of Economics and Statistics 57(1), 129-38

Joanis, M. (2014) 'Shared accountability and partial decentralization in local public good provision.' Journal of Development Economics 107, 28-37

Kotsogiannis, Christos, and Robert Schwager (2008) 'Accountability and fiscal equalization.' Journal of Public Economics 92(12), 2336-2349

Lovenheim, Michael F., and Emily G. Owens (2014) 'Does federal financial aid affect college enrollment? evidence from drug offenders and the higher education act of 1998.' Journal of Urban Economics 81(0), 1 - 13

Matsusaka, John G. (1995) 'Fiscal effects of the voter initiative: Evidence from the last 30 years.' Journal of Political Economy 103(3), 587-623

_ (2005) 'Direct democracy works.' Journal of Economic Perspectives 19(2), 185-206 
Micotti, Sébastian, and Gebhard Bützer (2003) 'Municipal democracy in switzerland: General view, institutions and experiences in the cities 1990-2000.' Rapport de recherche au FNS/SNF

Oates, Wallace (2005) 'Toward a second-generation theory of fiscal federalism.' International Tax and Public Finance 12(4), 349-373

Oster, Emily (2013) 'PSACALC: Stata module to calculate treatment effects or bounds under proportional selection of observables and unobservables.' Statistical Software Components, Boston College Department of Economics

_ (2014) 'Unobservable Selection and Coefficient Stability: Theory and Validation.' mimeo, University of Chicago Booth School

Redoano, Michela, and Kimberly A. Scharf (2004) 'The political economy of policy centralization: direct versus representative democracy.' Journal of Public Economics 88(34), 799-817 


\section{IdEP Economic Papers}

The series IdEP Economic Papers, ideally continues the work of the "Quaderni della Facoltà" the publication of which began in 1998 and ended in 2013.

For a complete list of the Quaderni see: http://econpapers.repec.org/paper/lugwpaper/

IdEP Economic Papers also gathers the legacy of the CEPRA Working Papers, published from 2012 to 2013.

The full list at: http://econpapers.repec.org/paper/lugwcepra/

\section{4:}

No. 01

F. Mazzonna, F. Peracchi, Unhealthy retirement? Evidence of occupation heterogeneity

No. 02

L. Di Giorgio, M. Filippini, G. Masiero, The relationship between costs and quality in nonprofit nursing homes

No. 03

F.C. Billari, V. Galasso, Fertility decisions and pension reforms : evidence from natural experiments in Italy

No. 04

M. Jametti, M. Joanis, Elections and de facto expenditure decentralization in Canada

No. 05

M. Jametti, Weathering the global financial crisis : is direct democracy of any help?

No. 06

U. Pagano, M. Vatiero, Costly institutions as substitutes: novelty and limits of the Coasian approach

No. 07

R. Parchet, Are local tax rates strategic complements or strategic substitutes?

No. 08

R. Ippoliti, M. Vatiero, An analysis of how 2002 judicial reorganization has impacted on the performance of the First Instance Courts (Preture) in Ticino

No. 09

F. Mazzonna, P. Salari, Short term effects of public smoking bans on health 
2015:

No. 01

S. Galletta, Direct democracy, partial decentralization and voter information : evidence from Swiss municipalities 